DOI: 10.1176/appi.ajp.2020.20030299; TOC Head: Letters to the Editor; Section Head: Communications and Updates

Article Type: Letters to the Editor; Collection Codes: , , , , ,

Letter to the Editor

Letter to the Editor

\title{
The Case for Cautious Interpretation and Replication: Lead-Time Bias as a Potential Explanation for the Link Between Duration of Untreated Psychosis and Outcome
}

Srividya N. Iyer, Ph.D.

Kelly K. Anderson, Ph.D.

Ashok Malla, MBBS, FRCPC

Jai Shah, MD, FRCPC

Ross Norman, Ph.D.

Department of Psychiatry and Department of Epidemiology, Biostatistics and Occupational Health, McGill

University, Montreal, Canada (Iyer, Malla, Shah); Prevention and Early Intervention Program for Psychosis, Douglas Mental Health University Institute, Montreal, Canada (Iyer, Malla, Shah); Department of Epidemiology and Biostatistics, Schulich School of Medicine and Dentistry, University of Western Ontario, London, Ontario, Canada (Anderson, Norman).

Send correspondence to Dr. Iyer (srividya.iyer@mcgill.ca).

\{Keywords:\} Psychosis, Early Intervention, Duration of Untreated Psychosis, Epidemiology, Treatment Delay, First-Episode Psychosis

TO THE EDITOR: Jonas and colleagues' "third hypothesis," as described in their article published in the April 2020 issue of the Journal, seeks to explain the important but poorly understood association between duration of untreated psychosis (DUP) and outcomes (1). We commend the authors for advancing the field by testing a novel theory using sophisticated analytic techniques. However, several issues warrant critical examination, lest the article's findings be construed as negating the need for reducing treatment delay.

First, the DUPs in this study are extremely long (mean days, 726, SD=94.89; mean weeks, 103.7; median days, 346; median weeks, 49.43) and may surpass a threshold beyond which longer-term outcomes may be uniformly low. Although the observed values may be "shorter" than those noted in the United States, as the authors state, they stand well above many estimates 
in the literature on the association between DUP and outcomes. Reviews have reported lower DUPs, with a 61.3-week mean (based on 33 studies) (2) and a 12-week median (based on 28 studies) (3). The World Health Organization and the International Early Psychosis Association consensus statement recommends that early intervention services achieve mean DUPs of under 3 months (4). This is supported by recent findings that extending early intervention improved outcomes only when the DUP was below this threshold $(5,6)$. Thus, even the study's "short" DUPs may miss the window of effectiveness for early intervention.

Second, the trends observed by the authors could be explained by more malleable, timevariant factors, particularly the quality of treatment received before and after the index hospitalization, which was deemed the endpoint for DUP. Lead-time bias arises when comparing groups at different stages in the natural history of a disease. Indeed, the natural history of psychoses can be altered by best-practice treatment, particularly early in the illness course, which would have changed functional trajectories in ways that this study could not capture. Notably, the treatment received by the study cohort is not comparable with current early psychosis treatment standards.

Thirdly, using a hospitalized sample limits generalizability. Currently, many patients access early intervention systems without ever being hospitalized. This selection bias is further exacerbated by high attrition across time points, which is likely nonindependent of functioning. In addition, the sample is not an epidemiological cohort representing the full spectrum of illness severity and DUP, which would be needed to truly understand the relationship between DUP and outcome trajectories.

Because this article could affect practice and policy, its methodological issues necessitate cautious interpretation and substantial replication among populations receiving care of presentday standards and in universal coverage systems. Finally, beyond its relationship to outcomes, shortening the DUP is unquestionably desirable because it reduces unnecessary suffering.

\section{REFERENCES}

1. Jonas KG, Fochtmann LJ, Perlman G, et al: Lead-time bias confounds association between duration of untreated psychosis and illness course in schizophrenia. Am J Psychiatry 2020; 177:327-334 $\underline{\text { PubMed }}</$ jrn $>$ 
2. Penttilä M, Jääskeläinen E, Hirvonen N, et al: Duration of untreated psychosis as predictor of long-term outcome in schizophrenia: systematic review and meta-analysis. Br J Psychiatry 2014; 205:88-94 $\underline{\text { PubMed }</ \text { jrn }>~}$

3. Boonstra N, Klaassen R, Sytema S, et al: Duration of untreated psychosis and negative symptoms: a systematic review and meta-analysis of individual patient data. Schizophr Res 2012; 142:12-19 $\underline{\text { PubMed }</ j r n>~}$

4. Bertolote J, McGorry P. Early intervention and recovery for young people with early psychosis: consensus statement. Br J Psychiatry 2005; 187(S48):s116-s119

https://pubmed.ncbi.nlm.nih.gov/16055800/

5. Dama M, Shah J, Norman R, et al: Short duration of untreated psychosis enhances negative symptom remission in extended early intervention service for psychosis. Acta Psychiatr Scand 2019; 140:65-76 PubMed $<$ /jrn>

6. Albert N, Melau M, Jensen H, et al: The effect of duration of untreated psychosis and treatment delay on the outcomes of prolonged early intervention in psychotic disorders. NPJ Schizophr 2017; 3:34 PubMed $</$ jrn $>$

Dr. Shah is supported by a clinician-scientist award from the Fonds de recherche du QuébecSanté. Dr. Iyer is supported by a salary award from the Canadian Institutes of Health Research. Dr. Malla has received honoraria for plenary lectures and presentations in symposia sponsored by Lundbeck and Otsuka and has received consultation fees for providing research consultation on a Canadian study. The other authors report no financial relationships with commercial interests.

Accepted June 15, 2020. 